\title{
Percepções de mulheres que utilizaram substâncias psicoativas durante a gestação quanto ao atendimento do profissional
}

\section{Perceptions of women who used psycho-active substances during the management of the professional attendance}

\author{
Vagner Ferreira do Nascimento ${ }^{1}$, Ingrid Karla Corrêa ${ }^{2}$, Ana Cláudia Pereira Terças ${ }^{3}$, Alisséia \\ Guimarães Lemes ${ }^{4}$, Margarita Antonia Villar Luis ${ }^{5}$
}

\section{Resumo}

Este estudo teve como objetivo conhecer as percepções de mulheres que utilizaram substâncias psicoativas durante a gestação quanto ao atendimento do profissional. Seguiu-se o método descritivoexploratório e com abordagem qualitativa. Participaram da pesquisa onze mulheres que utilizaram álcool e/ou outras substâncias psicoativas durante a gestação. A coleta de dados foi realizada entre março e maio de 2017 através de entrevista semiestruturada gravada. Utilizou-se a análise de conteúdo, à luz da Teoria de Peplau. A partir das narrativas, emergiram duas categorias: descoberta da condição de adicta pelo profissional e pontos positivos e negativos nos atendimentos. As participantes do estudo demonstraram satisfação pelas consultas de pré-natal, mas sinalizaram como ponto negativo a demora nos atendimentos, a comunicação difícil de médicos e formas desrespeitosas no cuidado hospitalar, passando por situações de violência. Diante disso, é importante rever a assistência ofertada às gestantes, em especial na condição de usuárias de drogas, para atenuar prognósticos materno-fetais desfavoráveis e não prejudicar a construção e manutenção das relações interpessoais entre clientes e profissionais.

Palavras chave: Assistência integral à saúde. Gestantes. Alcoolismo. Drogas ilícitas. Violência.

\begin{abstract}
This study aimed to know the perceptions of women who used psychoactive substances during pregnancy regarding the care of the professional. The descriptive-exploratory method followed with a qualitative approach. Eleven women who used alcohol and / or other psychoactive substances during pregnancy participated in the study. Data collection was carried out between March and May 2017 through a semi-structured recorded interview. Content analysis was used, in light of the Peplau Theory. From the narratives, two categories emerged: discovery of the addict's condition by the professional and positive and negative points in the consultations. The study participants demonstrated satisfaction with the prenatal consultations, but indicated as negative the delay in attendance, the difficult communication of doctors and disrespectful forms in the hospital care, through situations of violence. Therefore, it is important to review the assistance offered to pregnant women, especially as drug users, in order to mitigate unfavorable maternal-fetal prognoses and not to prejudice the construction and maintenance of interpersonal relationships between clients and professionals.
\end{abstract}

Keyword: Comprehensive health care. Pregnant women. Alcoholism. Street drugs. Violence.

\footnotetext{
${ }^{1}$ Doutorando em Bioética pelo Centro Universitário São Camilo, Brasil. E-mail: vagnerschon@hotmail.com

${ }^{2}$ Enfermeira pela Universidade do Estado de Mato Grosso; Campus Universitário de Tangará da Serra, Departamento de Enfermagem, Tangará da Serra, Mato Grosso, Brasil.

${ }^{3}$ Doutorado em Medicina Tropical pela Fundação Oswaldo Cruz; Docente Adjunta da Universidade do Estado de Mato Grosso, Campus Universitário de Tangará da Serra, Departamento de Enfermagem; Tangará da Serra, Mato Grosso, Brasil.

${ }^{4}$ Doutoranda em Enfermagem Psiquiátrica pela Escola de Enfermagem de Ribeirão Preto da Universidade de São Paulo; Docente Assistente da Universidade Federal de Mato Grosso, Campus Universitário do Araguaia, Departamento de Enfermagem; Araguaia, Mato Grosso, Brasil.

${ }^{5}$ Doutorado em Enfermagem pela Universidade de São Paulo. Docente Titular no Departamento de Enfermagem Psiquiátrica e Ciências Humanas da Escola de Enfermagem de Ribeirão Preto da Universidade de São Paulo; Ribeirão Preto, São Paulo, Brasil.
} 


\section{Introdução}

O uso de álcool, crack e/ou outras drogas por mulheres vem ganhando maiores proporções, principalmente pela iniciação e contato precoce, influenciadas por contextos sociais e econômicos (KASSADA et al., 2013). Esse comportamento tem reflexo negativo, pois quanto maior o tempo de exposição, mais complicado se torna a recuperação. Assim, muitas mulheres mesmo gestantes não conseguem parar ou diminuir o uso, principalmente se possuírem pessoas próximas que possuam relação com as drogas (SANTOS; GAVIOLI, 2017).

Portanto, as gestantes que consomem ou estão envolvidas rotineiramente com essas substâncias devem receber atenção especial, entendendo que o uso durante a gestação, pode acarretar problemas significativos para o desenvolvimento gestacional, como: subcrescimento fetal, abortos, partos prematuros, deformidades e déficits cognitivos no concepto (FONSECA et al., 2017). Contudo, muitas vezes essas mulheres são atendidas com pouca empatia, deparando-se com condutas autoritárias e repreensivas nos serviços de saúde. Outra questão, é que grande parte dos profissionais de saúde possuem pouco suporte teórico-científico para lidar com essas usuárias e isso desqualifica os atendimentos, dificultando o autocuidado, a socialização e o empoderamento da mulher (KASSADA; MARCON; WAIDMAN, 2014).

Sobretudo, habitualmente a adesão de mulheres em uso de substâncias psicoativas aos cuidados gestacionais é prejudicada, por se apresentarem vulneráveis e com poucas condições emocionais para gerenciar todas as demandas dessa fase de suas vidas. Algumas delas por se perceberem julgadas e marginalizadas, acabam não se sentindo confortáveis para revelar sua proximidade e relação com essas substâncias, omitindo informações e ampliando os riscos maternos (YABUUTI; BERNARDY, 2014).

Faz-se necessário que os serviços de saúde, desenvolvam estratégias para evitar abordagens desumanas e sem considerar a realidade das mulheres. Por conseguinte, é de suma importância que os profissionais de saúde entendam o contexto sociocultural do seu território de atuação, o que permitirá conhecer a história da cliente, suas fragilidades e potencialidades (WÜNSCH et al., 2012).

Para tanto, deve haver maior participação e interesse da sociedade na consolidação de políticas públicas que garantam efetivamente o exercício de uma assistência humanizada, de modo em especial, àquelas que contemplem questões negligenciadas e/ou invisibilizadas, como a dependência química feminina, em consideração à vulnerabilidade de gênero ligada às drogas (NASCIMENTO et al., 2017) e os desafios diante do acompanhamento gestacional desse grupo (LIMA et al., 2015). Além disso, há poucos investimentos em pesquisa que fomentam a compreensão sobre a mulher adicta e suas relações com os serviços sociais e de saúde (SOUZA; OLIVEIRA; NASCIMENTO, 2014), tendo predomínio ainda por estudos epidemiológicos e focados exclusivamente em alertar sobre impactos à saúde da mulher ou do concepto, pouco preocupados com os atravessamentos pessoais na busca por assistência e satisfação nos atendimentos recebidos. Deste modo, o estudo teve como objetivo conhecer as percepções de mulheres que utilizaram substâncias psicoativas durante a gestação quanto ao atendimento do profissional.

\section{Material e Métodos}

O estudo é de caráter descritivo-exploratório e com abordagem qualitativa. Sendo realizado em oito Unidades de Saúde da Família (USF) localizadas em um município do médio norte de Mato Grosso. A seleção dessas unidades foi através de amostragem aleatória simples e obedeceu aos seguintes critérios: ser uma unidade urbana, em funcionamento há pelo menos 24 meses, com a realização de consulta de enfermagem por profissionais como parte da rotina da assistência de pré-natal.

As participantes do estudo foram mulheres que utilizaram álcool e/ou substâncias psicoativas durante o período gestacional. A seleção das participantes respeitou critérios de inclusão e exclusão. Como critérios de inclusão: puérperas maiores de 18 anos, que realizaram no mínimo quatro consultas de prénatal nas USF selecionadas, que fizeram uso de álcool e/ou outras substâncias psicoativas durante o período gestacional. Foram excluídas, mulheres que possuíam convênio particular de saúde.

A coleta de dados ocorreu entre março e maio de 2017, empregando a técnica de entrevista semiestruturada gravada, norteada por um roteiro elaborado pelo pesquisador, contendo questões fechadas (aspectos sociodemográficos) e questões abertas (aspectos sobre como ocorria os atendimento durante o pré-natal e pré-parto, em especial diante da descoberta do uso/abuso de substâncias psicoativas 
pelo profissional de saúde). Foi durante o processo de coleta dos dados que definiu-se o quantitativo total de participantes do estudo, com base na exaustividade das informações de interesse, tal como proposto pela saturação amostral. Assim, a amostra final do estudou foi de onze mulheres.

As entrevistas foram transcritas na mesma semana da coleta e identificadas mediante códigos alfanuméricos (M1, M2, etc). Esse material foi organizado e sistematizado conforme os itens abordados no roteiro. O agrupamento inicial ocorreu por entrevista e em seguida as informações do conjunto (todas as entrevistas) foram agrupadas por semelhanças e diferenças.

Para análise foi utilizada a técnica de análise de conteúdo, à luz da Teoria das Relações Interpessoais de Peplau. Essa teoria propõe melhor adequação do processo terapêutico entre enfermeiro e o paciente, uma vez que passam a manter uma relação horizontal, onde ambos aprendem e crescem juntos como resultado dessa interação. Peplau identifica quatro fases sequenciais no relacionamento interpessoal: orientação, identificação, exploração e resolução. Cada fase é caracterizada por papéis ou funções do enfermeiro ou cliente, à medida que ambos aprendem a trabalhar, conjuntamente, de forma a resolver as dificuldades por eles enfrentadas e variam de acordo com as necessidades que surgem no decorrer do processo, até que passem a elaborar soluções para as demandas existentes (PEPLAU, 1990).

Foram respeitados todos os padrões éticos em pesquisa de acordo com a Resolução 466/2012 do Conselho Nacional de Saúde (CNS), iniciando o estudo somente após a aprovação do Comitê de Ética em Pesquisa com Seres Humanos (CEP) da Universidade do Estado de Mato Grosso (UNEMAT), sob número de CAAE: 61625316.0.0000.5166, parecer n. 1.889.354.

\section{Resultados e Discussão}

As participantes tinham idade entre 19 e 35 anos, em sua maioria em união estável, autodeclaradas pardas, protestantes evangélicas, com ensino fundamental incompleto, desempregadas, com renda familiar entre $\mathrm{R} \$ 70,00$ a $\mathrm{R} \$ 2.640,00$ reais, residindo em casa própria com filhos e companheiro. Iniciaram o uso de substâncias psicoativas entre 9 e 16 anos, tendo seu primeiro contato em ambientes familiares ou por influências de amigos. Sobre o histórico familiar, os pais de ambas não concluíram o ensino fundamental, fazem ou fizeram uso de alguma(s) substância(s) psicoativa(s) durante a vida, e vivenciaram momentos de violência.

Todas eram multíparas, sem históricos de aborto e com gestações não planejadas. Todas realizaram pré-natal em uma USF, iniciando as consultas com enfermeiro e as posteriores somente com o médico da unidade. Afirmaram em sua totalidade não terem recebido nenhuma orientação sobre parto e pós-parto durante a gestação, bem como atividades educativas sobre substâncias psicoativas e seus impactos na gestação. Muitas não realizaram todos os exames solicitados pelo profissional, alegando falta de interesse, problemas familiares ou descoberta tardia da gestação.

A maioria fez uso de drogas durante todos os dias ao longo da gestação, e aquelas que suspenderam o uso foi em razão de enjoos causados pelo cigarro, porém continuaram o consumo de álcool. Todas relataram manter o uso de substâncias psicoativas por não acreditar que faria mal ao bebê, uma vez que, alguns familiares e amigas se comportaram da mesma forma em suas gestações e seus bebes haviam nascido saudáveis. Entretanto, sabiam que o cansaço excessivo e indisposição percebidos durante a gestação eram efeitos das substâncias que utilizavam. Algumas conseguiram diminuir a frequência ou quantidade de drogas por conta própria após a gestação, mas ainda se consideram dependentes de alguma droga psicoativa (pasta base, cigarro de maconha, cigarro de palha, cigarro comum e/ou álcool), e não têm acompanhamento da unidade de saúde.

A partir das narrativas dessas mulheres, emergiram duas categorias de análise: "Descoberta da condição de adicta pelo profissional" e "Pontos positivos e negativos nos atendimentos".

\section{Descoberta da condição de adicta pelo profissional}

A descoberta da condição de usuária de substâncias psicoativas pelo profissional deve acontecer o mais precocemente possível, visando estabelecer projetos terapêuticos eficazes e que conduzam a desfechos gestacionais mais favoráveis. No entanto, pela própria característica da mulher usuária/dependente que sofre pelas consequências sociais impostas por esse uso/ abuso, muitas vezes esconde por entender/temer que punições ou julgamentos possam ser feitos. 
Normalmente circunstâncias relacionadas à dependência, como comportamentos e estilos de vida propiciam por si só essa descoberta.

Então eu acho que eles ficaram sabendo só depois da denúncia mesmo, [...] os vizinhos denunciaram, vieram atrás investigar, $e$ ai ficaram sabendo. Eles sabiam, mas não falaram nada para mim, e eu também não falei nada. (M1)

Eles ficaram sabendo por causa da agente de saúde. Eu contei pra ela depois, mas fiquei receosa. (M2)

Eles nos conhecem, às vezes não dormimos de noite e na hora da consulta sempre estamos com cara de cansada". Eu, por exemplo vou bem pouco ao posto, só quando preciso muito. Mas, ele só falou que eu deveria. (M3)

Eu contei pro médico que eu era viciada no cigarro e que não conseguia parar, assumi para não ter problemas depois. [...] Ah, problemas com o próprio profissional ou para fazer o pré-natal mesmo. (M5)

As vezes eu chegava nas consultas com cheiro de cerveja e meio ruim. Era visível o meu estado. (M6)

A pouca proximidade do profissional com essa clientela, gera incertezas na mulher quanto à identificação do papel e valorização do mesmo na assistência gestacional ou ainda a negação da própria mulher sobre sua condição, inibe relações interpessoais mais próximas. Pelas narrativas, os profissionais descobrem o uso mediante a vinda espontânea da mulher ou informações trazidas por outros (ACS, vizinhos). Esses profissionais parecem possuir dificuldade em desenvolver atitudes mais proativas para acolher essa clientela, o que tende a intensificar a perda progressiva dos vínculos.

A maioria das mulheres em uso de álcool e/ou outras substâncias psicoativas chegam aos serviços de saúde de forma indireta, ou por intercorrências clinicas. Há deficiências na captação dessas usuárias, e estudos apontam que o problema não se restringe ao aspecto político e gerencial das unidades de saúde, mas se inicia especialmente durante a formação do profissional, pois muitas informações e conteúdos importantes deixam de ser abordados, ou melhor, conduzidos enquanto vivência prática no enfrentamento dessa problemática social (PAULA et al., 2014).

Essa carência de conhecimentos impõe ainda obstáculos ao profissional no reconhecimento de queixas inespecíficas que podem estar associadas ao uso prejudicial ou a dependência, de modo a não oferecer uma assistência adequada e resolutiva (VARGAS; BICUDO, 2011).

A capacitação profissional favorece a detecção de contextos de risco ou o próprio uso de substâncias psicoativas. Ela auxilia no desenvolvimento de atividades de promoção à saúde e cultura da paz, uma vez que, a educação em saúde pode permitir a criação de novas formas de encarar o futuro e a promoção do autocuidado individual e familiar. Portanto, é imprescindível que a equipe de saúde intensifique as ações educativas para aproximar-se dessa clientela, articulando apoio junto à comunidade na qual essas mulheres convivem, no sentido de fortalecer as redes de cuidado (KASSADA et al., 2013). Essas relações mais próximas facilitam obter informações mais precisas sobre a realidade local, modos de vida e a incidência do uso; dados que amparam a avaliação e assistência contínua dessas clientes (DIAS et al., 2013).

Segundo a teoria das relações interpessoais, a enfermagem tem como objetivo ajudar os indivíduos e a comunidade a realizar mudanças que influencia de forma positiva suas vidas. Logo, as metas a serem atingidas devem ser estabelecidas pelo enfermeiro e pelo cliente, afim de não ocorrer resultados desarmônicos. Para conseguir esses resultados, é necessário reconhecer o papel do núcleo familiar, as possibilidades oferecidas pela comunidade e cultura destes clientes, caso contrário, os vínculos não serão estabelecidos (FRANZOI et al., 2016).

$O$ vínculo só é estabelecido através da confiança, na medida em que o profissional demonstre compreensão, respeito e atenção à mulher e a sua condição de vida. Essa interação entre cliente e profissional deve ser menos técnica e mais humanista, com foco na manutenção de um forte elo (SCHIMITH et al., 2012).

Todavia, no momento de descoberta do uso de substâncias psicoativas, os profissionais podem reforçar na mulher uma condição de usuária (SOUZA; OLIVEIRA; NASCIMENTO, 2014) ou conduzir diálogos fortemente repreensivos. E, talvez a reprodução dessa visão terapêutica distorcida em muitos cenários assistenciais faça outras mulheres não partilharem suas necessidades e sofrimentos. 
Eles já sabiam, porque eu tinha contado pra eles. E quando fiquei gravida da última vez eles chegavam em mim e falavam: você fuma, né?!. (M3)

[...] se você não deixar de usar, você sabe as consequências para o bebê ne?! (M5)

Eu não falei. Eu tinha medo de contar e eles chamar o conselho [tutelar] pra mim. E nas primeiras gestações eu era "de menor". Fiquei só pra mim mesmo. (M2)

[...] depois que contei eles ficaram falando que não podia por causa do bebe, eu falei pra eles que ia parar, mas não parei não, foi mentira. Falei isso só pra eles não ficar no meu pé. (M4)

$\mathrm{O}$ ato de assumir a condição de usuárias de substâncias psicoativas parece ser difícil para essas mulheres, em razão da resposta ou formas de acolhimento do profissional. Notadamente, gestantes que utilizam álcool e/ou outras drogas, é comum sentirem-se marginalizadas e julgadas pelos profissionais que as atendem. Em consequência, apresentam baixa adesão ao pré-natal e acabam escondendo sua condição, mesmo estando propensas a complicações fetais (MARANGONI, OLIVEIRA, 2013; YABUUTI, BERNARDY, 2014).

É comum ver profissionais realizando atendimentos com postura autoritária e estigmatizante, deixando de atender as demandas reais dos usuários do serviço e conduzindo atendimentos pobres e coercivos (PAULA et al., 2014). Outro aspecto é o pouco suporte teóricocientífico por parte destes profissionais, o que torna o atendimento deficiente na abordagem e na detecção de transtornos relacionados ao uso nocivo dessas substâncias. Não raro, esses profissionais demonstram desinteresse pela problemática e atitudes negativas frente aos clientes, o que leva a um acolhimento hostil e indiferente (KASSADA; MARCON; WAIDMAN, 2014; VARGAS, BICUDO, 2011).

As lembranças desses atendimentos potencializa nas mulheres perturbações que prejudicam as relações interpessoais, já que o indivíduo se comporta de acordo com a situação a que é exposto. Da mesma forma que Peplau reconhece que o crescimento mútuo e pessoal compartilhado entre o profissional de saúde e o cliente forma uma relação interpessoal importante para o pleno desenvolvimento do processo de cuidar (FRANZOI et al., 2016).
Deste modo, o foco do acolhimento baseado na portaria $\mathrm{n}^{\circ} 121$, de 25 de janeiro de 2012 se faz através da escuta, incentivando um processo de socialização, por meio de atividades terapêuticas, visando à redução de danos e interrupção ou redução do uso da substância psicoativa. Como suporte, enfatizam-se os programas culturais, educacionais e profissionalizantes, de acordo com as demandas de cada cliente, para geração de trabalho, renda e condições de moradia (LIMA et al., 2015).

Alguns profissionais já apresentam relações interpessoais mais favoráveis com esse público e talvez por este motivo ao descobrirem o uso/abuso de substâncias psicoativas reagem de modo mais compreensivo e respeitoso.

Ah reagiram normal, davam conselho pra eu parar de fumar né?! Só conversou normal, não acharam ruim e nem brigaram. O médico que falou que eu tinha que parar ou pelo menos diminuir por causa do neném. Porque isso podia prejudicar muito ele. (M3)

Mesmo após descobrirem, o atendimento deles foi bom. Foi um atendimento profissional mesmo. Eles me incentivaram a ir no CAPS [...]. (M1)

Eles me trataram igual estava tratando antes de contar pra eles que eu fumava. Só ficavam perguntando se eu tinha parado, que era pra "mim" tomar cuidado [...]. (M4)

Falou pra 'mim' diminuir ou parar porque podia afetar a criança, podia nascer com má formação. Mas ele não me julgou, nem fez cara feia quando eu contei. (M5)

Ah! Eles orientavam. Explicavam que não era bom por causa no bebê e tudo. Eles cobravam bastante. Mas não me tratavam mal. Dava pra ver que eles queriam o melhor pro bebê. (M6)

Como observado nas narrativas, fica evidente que quando o acolhimento e o vínculo entre profissionais e clientes são construídos, a qualidade do atendimento se amplia e qualifica. Pois, essa relação terapêutica se torna fortalecida e permite atenção individualizada e direcionada, com escuta ativa, diálogo, confiança e maior possibilidade de adesão às orientações (LIMA et al., 2015). 
Ainda assim, o atendimento coletivo envolvendo a família deve ser priorizado. Dentro deste atendimento deve-se levar em conta as intervenções psicossociais, que precisam ser realizadas de acordo com as necessidades particulares de cada gestante. Este suporte psicossocial é um conjunto de intervenções mais resolutivas, pois incentivam essas mulheres a participarem de terapêuticas específicas, estimulando o convívio social, através de terapia motivacional e grupos de apoio (MARANGONI, OLIVEIRA, 2013; WORLD HEALTH ORGANIZATION, 2014). Contudo, tal perspectiva não se observa nas narrativas das participantes, pois os profissionais centralizam sua atenção e preocupações na saúde do bebê, quando o foco, deveria voltar-se para o desenvolvimento da mãe e do filho.

Porém, as decisões sobre o tratamento e terapêutica devem se basear nos princípios da bioética, respeitando a autonomia da mulher e seu direito à privacidade $\mathrm{e}$ confidencialidade. Para tanto, é essencial fornecer informações claras e consistentes, alertando sobre os riscos que o consumo de álcool e outras drogas podem causar durante a gestação (GORDINHO, 2013; WORLD HEALTH ORGANIZATION, 2014), dando ênfase também aos danos à saúde da mulher durante $\mathrm{e}$ após a gestação.

O profissional deve demonstrar respeito, cuidado e preocupação à gestante. E ao incentivá-la e participar em conjunto da busca por escolhas saudáveis, pode-se sensibilizá-la quanto aos danos da manutenção do uso da substância psicoativa para o desenvolvimento do bebê e para a sua saúde. Esse processo terapêutico pode ajudá-la a preparar o seu grupo familiar para receber o filho em um ambiente mais receptivo (POGETTO, 2016).

Os pressupostos teóricos de Peplau recomendam que em novos espaços de cuidado sejam criadas novas formas de relacionamento com os clientes. $\mathrm{O}$ foco da assistência consiste na prática de identificação do problema e no atendimento das necessidades encontradas, construindo relações mútuas e interativas, sem preconceitos e obrigações pré-estabelecidas (D'ANTONIO et al., 2014), ajudando o cliente a reconhecer, reelaborar seus sofrimentos e enfrentar seus problemas (FRANZOI et al., 2016).

\section{Pontos positivos e negativos nos atendimentos}

Para o trabalho na USF é exigido dos profissionais contato íntimo, ético e próximo com a comunidade, pontos positivos que qualificam os atendimentos. Para a comunidade, os profissionais são valorizados por se mostrarem mais atenciosos, em especial quando participam na elaboração de seus planos de cuidados e na tomada de decisões frente ao seu estado de saúde. Entre as várias possibilidades de encontros como nas consultas de pré-natal, as falhas na comunicação do profissional e o mau gerenciamento do tempo dos atendimentos remetem a pontos negativos que tendem a diminuir a adesão ao pré-natal.

\begin{abstract}
O que eu mais gostava era isso mesmo que eu falei da própria consulta né?! Do atendimento em si, sempre me tirando todas minhas dúvidas e via como estava meu bebê, agora o que menos gostava era da espera, ter que ficar lá na sala esperando, então era só isso mesmo não tenho que reclamar. (M1)

Eu gostava de escutar o coraçãozinho do neném. Saber como ele estava. O que eu não gostava era do médico, eu não entendia o que ele falava, era muito rápido eu não entendia nada. Ele era cubano, preferia quando era brasileiro atendendo. (M2)
\end{abstract}

Eu gostava de ir lá, eles eram atenciosos, mas
às vezes demorava para me atender. O que
eu não gostava muito é que eu não entendia
muito bem que o médico falava, ele falava,
falava, de dez palavras que dizia eu entendia
três. Ele era cubano, falava e eu entendia
pouca coisa. (M4) Eu gostava de ouvir o coraçãozinho, a batida do coraçãozinho do neném. O que eu não gostava era da demora do atendimento. Onde eu fazia o pré-natal atendia muita gente, então demorava muito o atendimento, as vezes era uma manhã inteira. (M5)

Ah! nas consultas que a gente fica muito exposta né?! Erguer blusa e tudo. Isso eu não gostava, me incomodava. E agora o que eu gostava era de conversar com as outras gestantes. Porque tem o dia das consultas das gestantes, ai eu ouvia um pouco de tudo, cada uma contava uma história. (M6)

Fica claro nas narrativas que a forma como ocorria a condução das consultas de pré-natal foi determinante para (in)satisfação da gestante. E ainda que durante as consultas o profissional, de forma positiva, tenha 
desempenhado estratégias voltadas ao esclarecimento de dúvidas e facilitado à gestante a sensação de se ver mãe ao constatar a vitalidade do seu bebê; a falta de compreensão da gestante frente ao idioma utilizado pelo profissional e condutas específicas, causou malestar e situações de desagrado. Investigação realizada próximo da localidade deste estudo destacou a mesma percepção por outras mulheres quanto à dificuldade no entendimento de médicos cubanos, porém sem descontentamentos (NASCIMENTO, 2017), mas a permanência desses relatos pode influenciar negativamente a receptividade dessa assistência.

Os serviços de saúde precisam prover qualidade e ter bom desempenho. Este bom desempenho dos serviços de saúde é denominado responsividade, conceito que se refere aos aspectos não médicos do cuidado, atitudes compreensivas que visam através do apoio emocional e da bi-direcionalidade na comunicação, favorecer o desenvolvimento da autonomia e da autoafirmação. Deste modo, sob os preceitos de Peplau quando a comunicação profissional-cliente fica prejudicada, o processo de cuidado é comprometido (COMES et al., 2016).

O acompanhamento de gestantes usuárias de substâncias psicoativas deve estar atento às suas necessidades, observar seus contextos familiares e verificar em que ambientes oferecem a oferta de segurança e afeto. Nesse acompanhamento deve ser avaliada a condição individual de cada gestante e seus pares, encaminhando para serviço de referência conforme a necessidade identificada. Nestes casos, além do atendimento recebido pelo profissional é importante que essas mulheres troquem experiências com outras gestantes, aspecto valorizado pelas participantes do estudo. Ocasiões possibilitadoras do encontro de gestantes, incentivam a exposição de sentimentos e experiências vivenciados por elas, e poder compartilhá-las propicia a oportunidade de revelar suas limitações e dificuldades (LEITE et al., 2014; SOUZA, 2017), mas também suas potencialidades.

Deve-se ainda atentar ao tempo de espera e atendimento, para que este não se torne um obstáculo para a efetivação da assistência e satisfação das gestantes. Reclamações sobre o tempo disponibilizado para os atendimentos também são apontadas em outros estudos (ROCHA; ANDRADE, 2017). Entretanto, sabe-se que as consultas de pré-natal no serviço público fornecem dias e períodos agendados, porém sem horários específicos, tendo como regra o atendimento por ordem de chegada. Portanto, os profissionais precisam desenvolver ações que atendam a gestante, no tempo de suas carências e sofrimentos, com diálogo, olhar o necessário (VARGAS, 2012).

Para essa assistência é indispensável que os profissionais demonstrem empatia pela cliente independente de suas especificidades, para que ela se sinta acolhida, segura quanto à prática profissional e à vontade no atendimento (D'ANTONIO et al., 2014; PEPLAU, 1990). Algumas gestantes durante a consulta de pré-natal podem se sentir expostas e vulneráveis, devido à exposição de partes do seu corpo, o que reforça ao profissional a necessidade de reconhecer a intimidade e pudor dessa mulher, seguindo as diretrizes da teoria das relações interpessoais, determinando um momento específico para esclarecimentos, com comunicação clara e concisa, respeitando e valorizando as expressões manifestadas. Essa postura de respeito configura uma nova forma de se relacionar (SANTIAGO et al., 2013).

$\mathrm{Na}$ ambiência hospitalar, os atendimentos parecem não haver atingido plena satisfação das mulheres, e isso acarretou complicações imediatas.

Quando fui para o hospital já estava sentindo as dores. Eu disse para eles que não estava muito bem. Mas eles demoraram muito para me atender, eu achei que ia perder meu filho. Quando pedia alguma informação as mulheres que trabalhavam lá me trataram com casca e tudo mal respondiam o que eu perguntava. (M1)

Olha, quando eu fui ganhar eles me trataram bem. Ai depois que foi um horror. [...] deu problema depois que ganhei ele, minha placenta estava saindo pra fora, ai teve uma enfermeira que disse que o povo do SUS era $f^{* * *}$, porque não tem dinheiro, ai eu não gostei disso. Uma outra coisa que eu não gostei foi a forma como o médico atendeu uma outra gestante, foi muito grosso. Eu fiquei com medo de ser atendida igual. Eu me senti mal por ela. [...] o médico deixou a placenta dentro do útero, eles não limparam, só fecharam. Ai passei mal por causa da irresponsabilidade deles, eu perdi meu útero [...]. (M4)

Comecei a sentir as contrações, [...] não demorou muito tempo me levaram pra sala 
de cesárea, e eu não queria cesárea, queria normal. Foi aí que elas me amarraram. (M2)

Na minha primeira gestação quando eu fui ganhar eu achei que elas não tinham muita paciência. A forma de tratar, o jeito de tratar, como eu era mãe de primeira viagem, acho que não tinha aquele dialogo, aquela tranquilidade, aquela paciência. Eu acho que faltou profissional adequado pra ter essa parte desse tratamento. Me senti ofendida, porque elas não tinham uma forma adequada de tratar, elas eram muito bruta. (M5)

Foi assim, você sabe que no SUS encontra o que está de plantão lá né?! Até hoje eu não gosto do médico. Mas enfim, era final de semana. E quem estava atendendo era o Dr.***, já ouviu falar?! Fora que ele tem a fama né?! Eu morria de medo dele. Aquele homem é um grosso. No exame de toque, ele me machucou. Depois disso não fez mais nada. Mal me avaliou. Me lembro que uma técnica, eu acho, achou ruim comigo porque eu estava rindo. Mas eu estava feliz porque ia conhecer minha filha. O povo era muito mal humorado. (M6)

Todas as narrativas remetem a violações do corpo, dos desejos e das expectativas frente ao acolhimento e parto. A própria dinâmica desse tipo de serviço desfavorece relações interpessoais mais sólidas, porém não impedem que haja formas de acolhimento humanizado.

A violência em ambiente hospitalar se torna cada dia mais comum, pois até quando as maternidades dispõem de infraestrutura adequada pecam por recursos humanos falhos. As mulheres que dependem do serviço público de saúde, em sua maioria são descriminadas por conta da sua classe social e etnia (TOPA; NOGUEIRA; NEVES, 2016). Violência que também é violência de gênero, pois ocorre desvalorização da mulher, tendo seu corpo e sexualidade como elementos de domínio médico (BANDEIRA, 2014).

Alguns estudos apontam que a falta de conhecimento e o desrespeito relacionados aos direitos reprodutivos e sexuais das gestantes, por parte de alguns profissionais, e a imposição de regras e estigmas morais, são reconhecidos como fatores que desencadeiam os atos de violência contra as gestantes. Deste modo, as clientes se sentem sem valor, maltratadas física e moralmente, com sua intimidade exposta (BARBOZA; ALMEIDA
JUNIOR, 2017; GARRETT; OSELAME; NEVES, 2016). No entanto, o termo "violência institucional" não é conhecido e nem considerado pela maioria das mulheres, pois associam esta situação, a agressão física ou sexual e embora reconheçam os tratamentos negligentes, desrespeitosos e grosseiros, não adotam o termo violência (TERÁN et al., 2013).

Por outro lado, algumas experiências brasileiras já demonstram ser exitosas na redução da violência em maternidades públicas, especialmente com a estruturação e organização da atenção materno $\square$ infantil proposto pela Rede Cegonha, onde $82,9 \%$ de parturientes já demonstram certa satisfação e $89,4 \%$ se sentem seguras durante o processo de parto e pós parto (RODRIGUES et al., 2017). Mas, como ainda esses progressos são pontuais e isolados, o quadro de violência nacional sinaliza para a importância da humanização durante os atendimentos, de modo a garantir os direitos às mulheres desde a descoberta da gestação ao nascimento do bebê (TOPA; NOGUEIRA; NEVES, 2016).

Assim, a autonomia reprodutiva da mulher, bem como a autonomia do seu corpo deve ser respeitada (BARBOZA; ALMEIDA JUNIOR, 2017), com ou sem identificação da presença de uso de substâncias psicoativas. A partir disso, torna-se possível relações interpessoais fundamentadas na solidariedade e compaixão, podendo influenciar nas recorrências de violências (AGUIAR; D'OLIVEIRA; SCHRAIBER, 2013). Não esquecendo que contextos violentos contribuem para perpetuação dos mesmos comportamentos (PIRES et al., 2017).

Esses fatores predeterminam uma maior sensibilidade e conduta ética do profissional de enfermagem para novas formas de atender e relacionarse com a mulher durante a gestação, parto e puerpério, bem como dos demais integrantes da equipe de saúde. O repensar dos comportamentos e posturas atualmente exibidas nos contextos em saúde permite, conforme Peplau, a diminuição de situações de violência ou violações (PEPLAU, 1990).

As dinâmicas interpessoais no processo de cuidar são como chaves para a compreensão do comportamento humano, porém vemos constantemente a desconsideração do poder transformador dessas relações. A substituição do contato direto e diálogo compreensivo por formas particulares de assistência prejudica a construção coletiva do projeto terapêutico e o atendimento do profissional perde seu valor junto aos clientes. Assim, seguindo Peplau, o cuidado é, 
no seu núcleo, um processo interpessoal tanto para reconhecer uma ideia que deu forma ao nosso passado como para nos guiar para o nosso futuro (D'ANTONIO et al., 2014).

A utilização da Teoria das Relações Interpessoais e a oportunidade de dar voz às mulheres neste estudo ajudou a perceber com maior nitidez possibilidades de reduzir barreiras no estabelecimento de uma assistência humanizada; no entanto, o estudo ainda apresentou algumas limitações, como a falta de verificação sobre violência na gestação anterior da participante, uma vez que, grande parte das mulheres que sofreram violência na primeira gestação, ficam suceptiveis a nova ocorrência em outras gestações. Outra limitação foi não ter conseguido entrevistá-las logo após o parto, fator que pode ter interferido na pecepção das mesmas, pelo possível esquecimento dos fatos ou até mesmo perda da importância dos acontecimentos.

\section{Considerações Finais}

O estudo revelou que a maioria das mulheres em uso/ abuso de substâncias psicoativas chegam aos serviços de saúde de forma indireta, ocorrendo deficiências no acolhimento e continuidade da assistência. Foi possível observar fragilidades do profissional frente ao reconhecimento das singularidades dessas mulheres (suas histórias de vida e relações na comunidade), o que parece influenciar na adesão ao pré-natal.

Durante as consultas de pré-natal, em sua maioria se sentem satisfeitas, mas não acontece o mesmo na ambiência hospitalar, onde surgem vestígios de violência, principalmente psicológica e física. Verificou-se também que possuir contato direto com as drogas, aparentemente não foi o motivo que conduziu os profissionais durante a hospitalização para um acolhimento hostil e indiferente, o que levou a constatação de que trata-se de aspectos ligados às questões de gênero e/ou cultura profissional.

Espera-se com esse estudo auxiliar as discussões de novas estratégias para se alcançar e assistir esse grupo, na compreensão de suas vulnerabilidades e experiências danosas ligadas à gestação. Além disso, poderá permitir reflexões e feedback aos profissionais de saúde diante de suas práticas cotidianas, e isso promover atitudes positivas em prol dessas mulheres.

\section{Referências}

AGUIAR, J. M.; D’OLIVEIRA, A. F. L.; SCHRAIBER, L. B. Violência institucional, autoridade médica e poder nas maternidades sob a ótica dos profissionais de saúde. Cadernos de Saúde Pública, Rio de Janeiro, v. 29, n. 11, p. 2287-2296, 2013.

BANDEIRA, L. M. Violência de gênero: a construção de um campo teórico e de investigação. Sociedade e Estado, Brasília, v. 29, n. 2, p. 449-69, 2014.

BARBOZA, H. H. G.; ALMEIDA JUNIOR, V. A. (Des)igualdade de gênero: restrições à autonomia da mulher. Pensar, Fortaleza, v. 22, n. 1, p. 240-271, 2017.

COMES, Y.; TRINDADE, J. S.; SHIMIZU, H. E.; HAMANN, E. M.; BARGIONI, F.; RAMIREZ, L.; SANCHEZ, M. N.; SANTOS, L. M. P. Avaliação da satisfação dos usuários e da responsividade dos serviços em municípios inscritos no Programa Mais Médicos. Ciência e Saúde Coletiva, Rio de Janeiro, v. 21, n. 9, p. 2749-2759, 2016.

D’ANTONIO, P.; BEEBER, L.; SILLS, G.; NAEGLE, M. The future in the past: Hildegard Peplau and interpersonal relations in nursing. Nursing Inquiry, Carlton, v. 21, n. 4, p. 311-317, 2014.

DIAS, D. R.; SOUZA, R. M. P.; RODRIGUES, D. P.; ALVES, V. H.; MARCHIORI, G. R. S.; SILVA, L. A. O consumo de álcool e outras drogas na gestação: revisão integrativa. Revista de Enfermagem da UFPE, Recife, v. 7, n. 12, p. 7188-7199, 2013.

FONSECA A. P. B.; SOARES, M. L. B.; VIEIRA, V. M.; SOUSA, M. N. A. Prevalência e efeitos do uso de drogas na gestação em recém nascidos. Journal of Medicine and Health Promotion, Belo Horizonte, v. 2, n. 1, p. 515-526, 2017.

FRANZOI, M. A. H.; LEMOS, K. C.; JESUS, C. A. C.; PINHO, D. L. M.; KAMADA, I.; REIS, P. E. D. Peplau's interpersonal relations theory: an evaluation based on fawcett's criteria. Journal of Nursing UFPE, Recife, v. 10, n. 4, p. 3653-3661, 2016. 
GARRETT, C. A.; OSElAME, G. B.; NEVES, E. B. O uso da episiotomia no sistema único de saúde brasileiro: a percepção das parturientes. Revista Saúde e Pesquisa, Maringá, v. 9, n. 3, p. 453-459, 2016.

GORDINHO, C. C. F. Consumo de álcool e atitudes sobre a gravidez e a maternidade nas grávidas, utentes da Unidade Local de Saúde de Matosinhos. 2013. 61 f. Tese (Doutorado em Psicologia Clínica e da Saúde) - Faculdade de Educação e Psicologia, Universidade Católica Portuguesa, Porto.

KASSADA, D. S.; MARCON, S. S.; PAGLIARINI, M. A.; ROSSI, R. M. Prevalência do uso de drogas de abuso por gestantes. Acta Paulista de Enfermagem, São Paulo, v. 26, n. 5, p. 467-471, 2013.

KASSADA, D. S.; MARCON, S. S.; WAIDMAN, M. A. P. Percepções e práticas de gestantes atendidas na atenção primária frente ao uso de drogas. Revista da Escola Anna Nery, Rio de Janeiro, v. 18, n. 3, p. 428434, 2014.

LeITE, M. G.; RODRIGUeS, D. P.; SOUSA, A. A. S.; MELO, L. P. T.; FIALHO, A. V. M. Sentimentos advindos da maternidade: revelações de um grupo de gestantes. Psicologia em Estudo, Maringá, v. 19, n. 1, p. 115-124, 2014.

LIMA, L. P. M.; SANTOS, A. A. P.; POVOAS, F. T. X.; SILVA, F. C. L. O papel do enfermeiro durante a consulta de pré-natal à gestante usuária de drogas. Revista Espaço Saúde, Londrina, v. 16, n. 3, p. 39-46, 2015.

MARANGONI, S. R.; OLIVEIRA, M. L. F. Fatores desencadeantes do uso de drogas de abuso em mulheres. Texto \& Contexto em Enfermagem, Florianópolis, v. 22, n. 3, p. 662-670, 2013.

NASCIMENTO, V. F. Características de orientações recebidas durante as consultas de pré-natal. Saúde, Santa Maria, 2017. No prelo.

NASCIMENTO, V. F.; MOLL, M. F.; LEMES, A. G.; CABRAL, J. F.; CARDOSO, T. P.; LUIS, M. A. V. Percepção de mulheres em situação de dependência química no interior de Mato Grosso, Brasil. Cultura de los Cuidados, San Vicente del Raspeig, v. 21, n. 48, p. 33-42, 2017.
PAULA, M. L.; JORGE, M. S. B.; VASCONCELOS, M. G. F.; ALBUQUERQUE, R. A. Assistência ao usuário de drogas na atenção primária à saúde. Psicologia em Estudo, Maringá, v. 19, n. 2, p. 223233, 2014.

PEPLAU, H. E. Relaciones interpersonales em enfermería: um marco de referência conceptual para la enfermería psicodinámica. Barcelona: MassonSalvat, 1990.

PIRES, M. R. M.; LOCATELLI, T. Z.; ROJAS, P. F. B.; LINDNER, S. R.; BOLSONI, C. C.; COELHO, E. B. S. Prevalência e os fatores associados da violência psicológica contra gestantes em capital no sul do Brasil. Saúde \& Transformação Social, Florianópolis, v. 8, n. 1, p. 29-39, 2017.

POGETTO, M. R. B. D. Redes de atenção à saúde para gestantes usuárias de álcool elou outras drogas. 2016. 125 f. Tese (Doutorado em Saúde Coletiva) Universidade Estadual Paulista "Júlio de Mesquita Filho", Faculdade de Medicina, Botucatu, 2016.

ROCHA, A. C.; ANDRADE, G. S. Atenção da equipe de enfermagem durante o pré-natal: percepção das gestantes atendidas na rede básica de ItapurangaGO em diferentes contextos sociais. Revista de Enfermagem Contemporânea, Brotas, v. 6, n. 1, p. 30$41,2017$.

RODRIGUES, F. A. C.; LIRA, S. V. G.; MAGALHÃES, P. H.; FREITAS, A. L. V.; MITROS, V. M. S.; ALMEIDA, P. C. Violência obstétrica no processo de parturição em maternidades vinculadas à Rede Cegonha. Reprodução \& Climatério, São Paulo, v. 32, n. 2, p. 78-84, 2017.

SANTIAGO, R. F.; MENDES, A. C. G.; MIRANDA, G. M. D.; DUARTE, P. O.; FURTADO, B. M. A. S. M.; SOUZA, W. V. Qualidade do atendimento nas Unidades de Saúde da Família no município de Recife: a percepção do usuário. Ciência e Saúde Coletiva, Rio de Janeiro, v. 18, n. 1, p. 35-44, 2013.

SANTOS, R.M.S.; GAVIOLI, A. Risco relacionado ao consumo de drogas de abuso em gestantes. Revista Rene, Maringá, v. 18, n. 1, p. 35-42, 2017. 
SCHIMITH, M. D.; SIMON, B. S.; BRÊTAS, A. C. P.; BUDÓ, M. L. D. Relações entre profissionais de saúde e usuários durante as práticas em saúde. Trabalho, Educação e Saúde, Rio de Janeiro, v. 9 n. 3, p. 479503, 2012.

SOUZA, M. L. M. Rodas de conversas em saúde: uma estratégia de metodologia participativa no acompanhamento pré-natal de gestantes usuárias de um serviço de saúde. 2017. 28 f. Monografia (Especialização em Linhas de Cuidado em Enfermagem) - Universidade Federal de Santa Catarina, Florianópolis.

SOUZA, M. R. R.; OLIVEIRA, J. F; NASCIMENTO, E. R. A Saúde de mulheres e o fenômeno das drogas. Texto \& Contexto em Enfermagem, Florianópolis, v. 23, n. 1, p. 92-100, 2014.

TERÁN, P.; CASTEllanos, C.; BlANCO, M. G.; RAMOS, D. Violencia obstétrica: percepción de las usuárias. Revista de Obstetricia y Ginecología de Venezuela, Caracas, v. 73, n. 3, p. 171-180, 2013.

TOPA J. B.; NOGUEIRA, C.; NEVES, S. Vivências de mulheres brasileiras nos serviços de saúde materna. Gênero Direito, João Pessoa, v. 5, n. 2, p. 25-51, 2016.

VARGAS, D.; BICUDO, D. F. A. Enfermeiros dos centros de atenção psicossocial em álcool e drogas (caps ad): a formação e a busca pelo conhecimento específico da área. Texto \& Contexto em Enfermagem, Florianópolis, v. 20, n. 1, p. 119-126, 2011.

VARGAS, E. P. 'Barrigão à mostra': vicissitudes e valorização do corpo reprodutivo na construção das imagens da gravidez. História, Ciências, SaúdeManguinhos, Rio de Janeiro, v. 19, n. 1, p. 237-2, 2012.

WORLD HEALTH ORGANIZATION - WHO. Guidelines for the identification and management of substance use and substance use disorders in pregnancy. Genebra, 2014.

WÜNSCH, S; BUDÓ, M. L. D.; GARCIA, R. P.; OLIVEIRA, S. G.; GEWEHR, M.; SCHIMITH, M. D.; SILVEIRA, C. L. População rural e enfermagem: uma revisão bibliométrica. Revista de Enfermagem da UFSM, Santa Maria, v. 2, n. 3, p. 539-546, 2012.
YABUUTI, P. L. K.; BERNARDY, C. C. F. Perfil de gestantes usuárias de drogas atendidas em um centro de atenção psicossocial. Revista Baiana de Saúde Púbica, Salvador, v. 38, n. 2, p. 344-356, 2014. 
do Nascimento, V. F.; et al. 